УДК 621.398

DOI 10.36910/6775-2313-5352-2020-16-14

Сахацкий В. Д., Скомороха В. Ю.

Харьковский национальный автомобильно-дорожный университет

\title{
УСТРОЙСТВО СОПРЯЖЕНИЯ ВОЛНОВОДНОЙ ЛИНИИ ПЕРЕДАЧИ В СИСТЕМЕ ИЗМЕРЕНИЯ ПРОСТРАНСТВЕННОГО ПОЛОЖЕНИЯ ПРОКАЛЫВАЮЩЕЙ ГОЛОВКИ МЕХАНИЗМА ПОДЗЕМНОЙ ПРОКЛАДКИ КОММУНИКАЦИОННЫХ TPACC
}

\begin{abstract}
Аннотация. В статье рассматривается способ повышения эффективности измерительной системы определения пространственного положения прокальвающей головки механизма прокола грунта, в которой на частоте 5 ГГи полье металлические штанги могут использоваться в качестве линии передачи измерительного сигнала. Учитывая, что такая линия за счет своей неоднородности изменяет поляризацию промедмей волны, предложена конструкция устройства сопряжения круглого волновода с коаксиальным входом приемного устройства, которая позволяет на его входе увеличить уровень сигнала. Проведенные экспериментальные исследования на макете линии передачи с рабочей частотой 10 ГГи подтвердили эффективность предложенного устройства сопряжения.

Ключевые слова: кругльй волновод, коэффициент передачи, коаксиальный волновод, неоднородность, деполяризачия волны, уровень сигнала.
\end{abstract}

Введение и постановка задачи. В настоящее время во многих странах мира прокладка различных видов подземных коммуникаций осуществляется без разрушения верхних слоев грунта. Для этого используют метод горизонтально-направленного прокола (бурения) грунта с помощью специальных механизмов прокола (бурения). Чаще всего непосредственным прокалывающем элементом является прокалывающая головка или пневмопробойник. В процессе прокола грунта нельзя допустить, чтобы траектория прокалывающей головки отклонялась от заданной трассы, так как такое отклонение не только не обеспечивает выход коммуникационной системы в заданную точку, но также может привести к столкновению прокалывающей головки с другими коммуникационными системами и разрушению их.

Причинами отклонения трассы от заданной являются неточность начальной установки оси механизма прокола относительно оси трассы, различная плотность и каменистость грунта, изгиб наращиваемых штанг, которые проталкивают прокалывающую головку в грунте.

Коррекция траектории движения прокалывающего органа и определение его подземного пространственного положения является одной из основных задач при горизонтально-направленном проколе грунта. Поэтому механизмы прокола необходимо снабжать системами контроля и управления траекторией движения прокалывающей головки. В настоящее время существуют различные методы определения координат прокалывающей головки, которые зависят от конструкции механизма прокола, особенностей грунта, глубины и длины трассы.

Бестраншейная прокладка коммуникационных трасс в городской черте накладывает определенные трудности на использование известных методов и средств такой прокладки. Вопервых работа в стесненных городских условиях вызывает необходимость разработки малогабаритных механизмов прокола. Во- вторых городская среда характеризуется широким частотным спектром индустриальных электромагнитных помех. Данные обстоятельства приводят к тому, что известные прокалывающие механизмы и системы определения координат прокалывающей головки в городской черте зачастую неприменимы. Поэтому поиск эффективных методов создания помехозащищённых измерительных систем, привязанных к конкретному малогабаритному механизму прокола, является актуальной задачей.

Анализ последних исследований и публикаций. Измерение пространственных координат подземных трасс является неотъемлемым атрибутом при прокладке газовых, нефтяных, геотермальных и других скважин. В этом случае в качестве основного метода измерения используют инклинометрический метод. Инклинометр включает в себя скважинный и наземный приборы. В скважинном приборе для измерения азимута и зенитного угла скважины имеются датчики, которые реагируют на изменение магнитного и гравитационного поля земли. Питание скважинного прибора осуществляется с помощью специального картонажного кабеля от наземного прибора. По тому же картонажному кабелю наземный 
прибор получает информацию от датчиков об угловых положениях скважины [1]. При определении пространственных координат скважин используются различные виды инклинометров. Их усовершенствование связано с разработкой более чувствительных датчиков и с повышением точности измерения.

Интенсивное развитие бестраншейного метода создания трасс подземных коммуникаций вызвало появление новых и усовершенствование известных механизмов прокола грунта, что повлекло за собой создание и развитие соответствующих им измерительных систем определения координат прокалывающего органа. Используемые при формировании подземных трасс методы и механизмы прокола, описаны в работе [2]. Такие механизмы обычно использовались для прокола грунта на больших площадях, поэтому имеют большие габариты и для работы в стесненных городских условиях являются малопригодными.

Для работы в городской черте в настоящее время разрабатываются малогабаритные механизмы прокола [3]. При этом технологический процесс прокола требует непрерывного контроля за пространственным положением прокалывающей головки и своевременной корректировки ее траектории [4].

Наибольшее распространение при определении подземных координат движущихся металлических объектов получили электромагнитные методы: радиопросвечивания, радиолокационный, феррозондовый и индукционный, которые достаточно подробно описаны в диссертационной работе Плешаковой Е.В. [5]. При этом, как правило, при проколе грунта используется импортное оборудование, такое как навигационная система МАГстир (английская фирма Impacdrilling LTD), системы позиционирования Mark 111, 1V, V, Eclipse (компания Digitrack, Германия) и другие [5]. Процесс прокола грунта в большинстве случаях осуществляется с помощью пневмопробойника как источника электромагнитного поля. Для этого в его конструкцию включают устройства, создающие вне пробойника магнитное поле или электромагнитное излучение. Приемник располагается на поверхности земли и по прошедшему через слой грунта электромагнитному (магнитному) полю определяет место положения пневмопробойника и направление его движения. В [5] отмечено, что большинство таких систем работают в низкочастотном диапазоне, подвержены воздействию индустриальных помех и не всегда обеспечивают высокую точность определения координат пробойника.

В настоящее время для повышения точности и помехозащищенности измерительных систем механизмов прокола грунта их разработки проводятся в более высоком диапазоне частот. При этом используют две разнесенные в пространстве приемные антенны. По принимаемому антеннами уровню или запаздыванию во времени электромагнитных сигналов от излучателей пробойника, судят о месте его положения и направлении движения.

Так в [6] описан способ измерения угла отклонения пневмопробойника от заданной траектории. Конструкция пробойника выполнена в виде несимметричного вибратора с рабочей частотой 150 МГц. Излучение вибратора принимается двумя антеннами, которые располагаются перед пробойником симметрично оси траектории трассы. Высокочастотные колебания на вибратор подаются от наземного генератора с помощью радиочастотного кабеля, который протягивается вдоль выполненной пневмопробойником трассы. По разнице уровней принятых антеннами сигналов определяют угол ее отклонения.

Данный способ обеспечивает повышение помехозащищенности измерительной системы и точность измерения угла отклонения трассы от заданного направления. К его недостаткам можно отнести возможность измерения только в горизонтальной плоскости, а также требование, чтобы приемники располагались в приямке на уровне пневмопробойника. Последнее при достаточно длинной трассе вызывает необходимость дополнительного разрушения поверхностного слоя.

В целом анализ литературных источников показывает, что действующие механизмы прокола грунта, методы и системы измерения (контроля) прокладываемой трассы являются крупногабаритными, имеют сложное техническое исполнение, вызывают необходимость дополнительных расчетов для определения пространственного положения прокалывающего органа, характеризуются большой стоимостью (десятки тысяч долларов для импортных систем). Их использование совместно с последними разработками малогабаритных прокалывающих установок статического действия при работе в сложных городских условиях зачастую невозможно. Линией передачи измерительного сигнала к приемнику обычно является поверхностный слой грунта, что затрудняет за счет больших потерь использование высокочастотного диапазона.

(С) Сахацкий В. Д., Скомороха В. Ю. 
В процессе прокола грунта в большинстве известных измерительных систем приемник переносится так, чтобы он все время находился над источником излучения. Если на земной поверхности в направлении прокладываемой трассы будут находиться какие - либо строения, то непрерывный прием измерительного сигнала, несущего информацию о текущем направлении движения прокалывающего органа будет невозможен и, как следствие, возникает неуправляемый прокол грунта по произвольному направлению.

Корректировку трассы можно осуществить с помощью специальной конструкции наконечника прокалывающей головки. Поворачивая прокалывающую головку в процессе движения вокруг своей оси на заданный угол можно изменять направление ее движения [4].

Осуществить такой управляемый прокол грунта можно только с помощью информационно-измерительной системы, позволяющей определить углы отклонения головки от заданной трассы в горизонтальной и вертикальной плоскостях и угол поворота вокруг ее оси.

В работе [7] показано, что для малогабаритных механизмов прокола при использовании $\mathrm{Wi}$-Fi технологий с несущей частотой 5 ГГц возможно создание измерительной системы для управляющего прокола грунта. При этом линией передачи измерительного сигнала (волноводной) могут служить стальные полые круглые штанги малогабаритного механизма прокола, которые обеспечивают продвижение в грунте прокалывающей головки. Проведенные теоретические исследования показали, что неоднородности, обусловленные стыком последовательно наращиваемых штанг, и удельная электропроводность стали позволяют без дополнительного усиления обеспечить уверенный прием измерительного сигнала об угловых положениях прокалывающей головки на расстоянии 50 м, что вполне приемлемо для работы в городской среде. Вместе с тем любая неоднородность в волноводной линии передачи приводит к изменению поляризации прошедшей волны и, как следствие, вызывает уменьшение уровня сигнала на входе приемника, настроенного на прием волны конкретного вида поляризации. Поэтому вопросы обеспечения уверенного приема измерительного сигнала для данной измерительной системы при деполяризации волны, распространяющейся по волноводной линии остаются открытыми.

Цель работы. Разработка и экспериментальное исследование устройства сопряжения волноводной линии передачи с приемной частью измерительной системы малогабаритных механизмов управляющего прокола грунта при приеме деполяризованной волны.

Изложение материалов исследования. Представление о малогабаритном механизме прокола грунта дает рис.1.

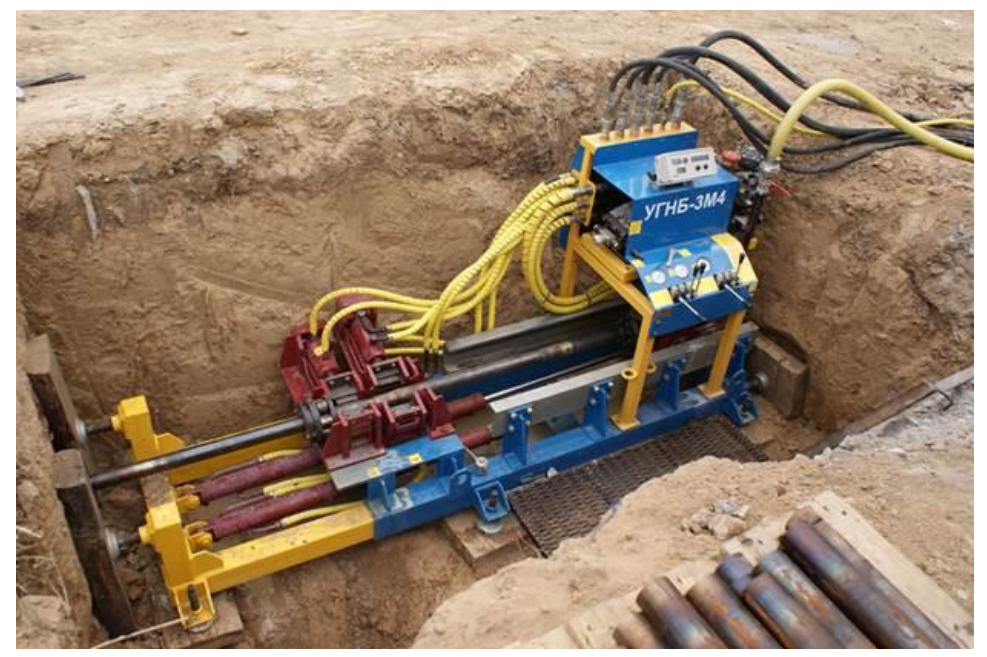

Рис. 1. Малогабаритный механизм прокола грунта [3]

В данном механизме продвижение прокалывающей головки осуществляется с помощью показанных на рис. 1 штанг в виде стальных труб длиной 50 см, внутренний и внешний диаметры которых соответственно равны 3,95 см и 6,35 см. Такая штанга является круглым волноводом, по которому на частоте 5 ГГц может распространяться основной $\mathrm{H}_{11}$ тип колебаний. Эти штанги и предлагается использовать для передачи измерительного сигнала от прокалывающей головки. Штанги соединяются друг с другом резьбовым соединением и механизм прокола может вместе с

(C) Сахацкий В. Д., Скомороха В. Ю. 
прокалывающей головкой поворачивать их вокруг своей оси на заданный угол для управления траекторией движения.

Частоту 5 ГГц относят к рабочим частотам Wi-Fi систем. Сама измерительная система, построенная на основе Wi-Fi модулей состоит из передатчика и приемника. Передатчик размешается в полости прокалывающей головки, а приемник - вместе расположения прокалывающего механизма. В качестве передатчика может выступать миникомпьютер Raspberry Pi 3 Model B+ c подключенным к нему датчиком пространственного положения BMX055 [7].

Приемник реализован в виде миникомпьютера Raspberry $\mathrm{Pi} 3$ Model $\mathrm{B}+\mathrm{c}$ подключенным к нему дисплеем для вывода информации. Данная система позволяет определять углы поворота прокалывающей головки в горизонтальной и вертикальной плоскостях, а также угол ее поворота вокруг своей оси. Расстояние, которое прошла прокалывающая головка, можно определить по числу подсоединяемых в процессе движения штанг.

Принцип измерения пространственного положения головки с учетом специфики применяемых для частоты 5 ГГц Wi-Fi модулей будет таким же, что и указанный в работе [8].

Предлагаемая измерительная система позволяет получать непрерывную информацию о пространственном положении прокалывающей головки вне зависимости от наличия на земной поверхности различных преград и осуществлять управляющий прокол грунта. Прокол можно осуществлять на произвольных глубинах прокладываемой трассы не зависимо от электрофизических параметров грунта. Уровень принимаемого сигнала будет зависеть только от его потерь в линии передачи и в устройствах ее сопряжения с передатчиком и приемником измерительной системы.

Наиболее просто устройство сопряжения волноводной линии передачи с приемником можно было бы выполнить в виде волноводного перехода с круглого сечения на коаксиальную линию. Подсоединив его к выходу волноводной линии и вращая вокруг своей оси, можно обеспечить согласование поляризаций волны на выходе линии с волной в коаксиально волноводном переходе и получить максимальную входную мощность измерительного сигнала на приемнике. Однако возбуждающий штырь и его входное отверстие в коаксиально волноводном переходе на круглом волноводе сами являются неоднородностью и также будут изменять уже согласованную на входе волноводного перехода поляризацию волны. Выполнять штанги в виде эллиптических волноводов, как это делается для ликвидации поляризационного вырождения волны типа $\mathrm{H}_{11}$ в специальных линиях передачи, технически сложно и дорого. Более простой способ устранения поляризационного вырождения волны состоит в изготовлении устройства сопряжения в виде волноводного перехода с круглого волновода на прямоугольный, к которому подсоединяется коаксиально -волноводный переход на прямоугольном волноводе. Последний, как и эллиптический волновод, не допускает поляризационного вырождения волны типа $\mathrm{H}_{11}$, преобразующуюся в волну типа $\mathrm{H}_{10}$.

Подобную конструкцию возбуждающего устройства целесообразно устанавливать и на входе волноводной линии, чтобы исключить возможность поляризационного вырождения волны типа $\mathrm{H}_{11}$ на стадии ее возбуждения. Следует отметить, что выполнить такое устройство сопряжения можно на основе стандартных составляющих его элементов, что удешевляет конструкцию. При этом необходимо иметь ввиду, что при малых размерах приямка для механизма прокола требуются небольшие по длине волноводные переходы, которые имеют более высокое значение КСВ.

Сравнивая картину распределения волны типа $\mathrm{H}_{11}$ в круглом волноводе и волны типа $\mathrm{H}_{11}$ в коаксиальной линии, можно заметить, что в коаксиальной линии напряженность электрического поля в большей степени концентрируется вблизи ее центрального проводника. Аналогичная картина наблюдается и вблизи металлического выступа в П- образном волноводе. Возбуждающий штырь коаксиально-волноводного перехода расположен вблизи центральной части волновода. Поэтому концентрируя поле вблизи оси волноводного перехода можно увеличить напряженность поля вблизи штыря и тем самым увеличить амплитуду ТЕМ волны в коаксиальном волноводе.

Экспериментальное подтверждение изложенного проводилось для макета линии передачи на частоте 10 ГГц (кратной рабочей частоте 5 ГГц). В качестве модели металлических штанг использовались отрезки стальной трубы длинной 50 см с внутренним и внешним диаметром равными соответственно $2,18 \mathrm{~cm}$ и $2,68 \mathrm{~cm}$. Такие штанги на частоте 10 ГГц также могли поддерживать волну типа $\mathrm{H}_{11}$. Отрезки волноводов (во избежание перекосов) соединялись между собой с помощью картонных трубок, которые плотно входили во внутренний диаметр волновода.

(С) Сахацкий В. Д., Скомороха В. Ю. 
Неоднородностью линии передачи служил стык двух волноводов, а излучение из цилиндрической щели стыка экранировалось с помощью алюминиевой фольги, которая охватывала внешний диаметр волновода.

Макет устройства сопряжения изготавливался на основе стандартного для частоты 10 ГГц круглого волновода длиной 9 см и волноводного перехода с круглого на прямоугольный волновод длиной 12 см. Моделью коаксиально волноводного перехода служила детекторная секция, которая по своей структуре аналогична ему с тем отличием, что возбуждающим штырем в ней является цилиндрический диод, осуществляющий одновременно прием и преобразование радиоизлучения в низкочастотный информационный сигнал. Вдоль оси устройства сопряжения с помощью пенополиуретановых втулок устанавливались покрытые фольгой металлические стержни разного диаметра и длины, образуя отрезок коаксиальной линии. Для согласования с волноводной линией их концы имели конусообразную форму высотой 4 см. Общий вид макетов устройства сопряжения и измеритеьной установки с линией передачи показан на рис. 1. и рис.2.

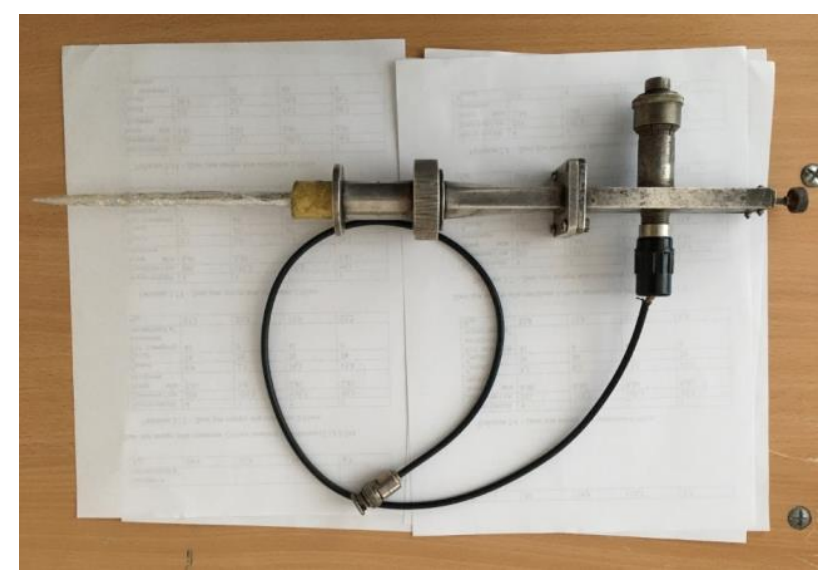

Рис.1. Общий вид макета устройства сопряжения

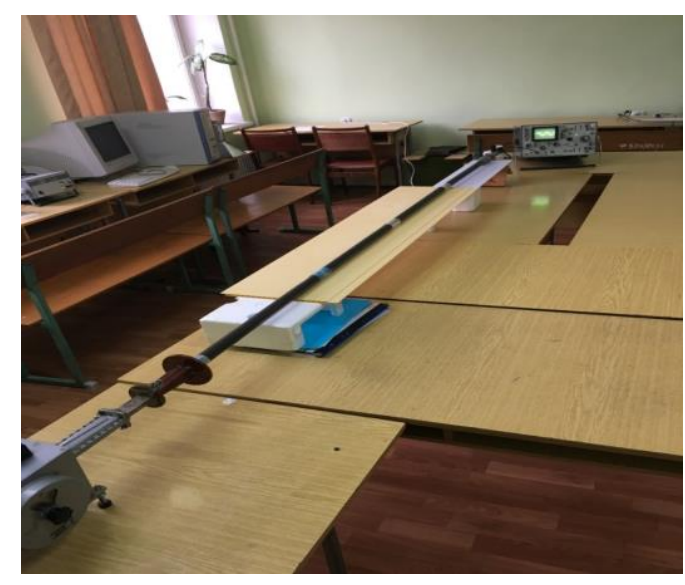

Рис.2. Общий вид измеритеьной установки

Методика измерения состояла в следующем. От генератора стандартних сигналов типа Г4-32А через аттенюатор типа Д5-5 импульсно- модулированное излучение с помощью волноводного перехода с прямоугольного на круглый преобразовывалось в волну типа $\mathrm{H}_{11}$, распространяющуюся по состыкованным друг с другом четырем отрезкам круглого волновода. Прошедшая деполяризованная волна принималась макетом устройства сопряжения, детектировалась и прямоугольный модулирующий сигнал фиксировался осциллографом типа C1-64A.

Измерительная установка позволяла определить степень деполяризации прошедшей волны и размеры металлического стержня устройства сопряжения, обеспечивающих максимальный уровень принятого сигнала.

Степень деполяризации прошедшей волны определялась путем поворота устройства сопряжения вокруг своей оси до получения максимального уровня выходного сигнала

Оптимальная конструкция устройства сопряжения определялась по минимальному значению коэффициента передачи, который находился как отношение уровня сигнала на входе волноводной линии и на выходе устройства сопряжения. Для этого детекторная секция подсоединялась к выходу аттенюатора и регулируя его уровень ослабления добивались показаний амплитуды сигнала на ее выходе равной 5 мВ. Затем к выходу аттенюатора подключалась линия передачи, вращением вокруг оси устройства сопряжения добивались максимального уровня выходного сигнала и вновь регулировкой аттенюатора устанавливался выходной сигнал с амплитудой 5 мВ. Разница в показаниях аттенюатора представляла собой значение коэффициента передачи (ослабления), выраженного в децибелах. 
Результаты измерений показали, что по сравнению с устройством сопряжения, в котором отсутствовал металлический стержень, установка стержня диаметром $0,815 \mathrm{~cm}$ и длиной 14,3 см, при глубине его погружения в волноводный переход на расстояние $\Delta$ $=2 \mathrm{~cm}$ (отсчет от торца его круглого сечения), уровень выходного сигнала увеличился на 3 дБ. При этом угол деполяризации волны был равен $0^{0}$. При глубине погружения $\Delta$ $=4 \mathrm{~cm}-$ на 5,8 дБ, а угол деполяризации стал равным $20^{0}$. При глубине погружения $\Delta=$ 5,5 см - на 5,3 дБ, а угол деполяризации возрос до $40^{\circ}$. В процессе исследования проводились пятикратные повторные измерения, погрешность которых не превышала \pm 2.6 дБ. Таким образом предложенная конструкция устройства сопряжения подтвердила свою эффективность. Физически это можно объяснить теми же эффектами, которые имеют место в коаксиально- волноводных переходах, когда в них для увеличения выходной мощности используют волноводные диафрагмы или согласующие трансформаторы в виде штырей [9].

При дальнейших измерениях проводились сравнительные оценки коэффициента передачи волноводной линии с различными конструкциями устройства сопряжения. Исследовалось влияние на коэффициент передачи стержней различных геометрических размеров (с длинами 14,3 cм, 18,7 cм, 30,5 см и диаметрами $0,815 \mathrm{~cm}, 0,847$ см и $1,06 \mathrm{~cm}$ ). Лучшие результаты показал стержень длиной 18,7 см и диаметром 1,06 см. В частности, при глубине его погружения $\Delta=4$ см получен коэффициент передачи линии равный 5,8 дБ. При глубине погружения $\Delta=7$ см $-8,5$ дБ, а при глубине погружения $\Delta=8 \mathrm{~cm}-10,6$ дБ. Анализ полученных результатов показал, что наименьшее затухание в линии передачи (минимальный коэффициент передачи) обеспечивает стержень диаметром 1,06 см при его длине 18,7 см и глубине погружения $\Delta=4 \mathrm{~cm}$.

Выводы:

1. Рассмотрен способ увеличения уровня сигнала на входе приемника измерительной системы при использовании штанг малогабаритного механизма прокола грунта, как волноводной линии передачи с изменяющейся поляризацией волны.

2. Предложена конструкция устройства сопряжения волноводной линии передачи с приемной частью измерительной системы, которая по сравнению с известными волноводными конструкциями является более эффективной.

3. Для макета волноводной линии с рабочей частотой 10 ГГц экспериментально найдены геометрические размеры устройства сопряжения, обеспечивающие максимальный уровень сигнала на входе приемника.

Дальнейшие исследования предполагают испытание и доработку предложенной конструкции устройства сопряжения для измерительной системы на частоте 5 ГГц.

\section{Литература}

1. Исаченко В.Х. Инклинометрия скважин .- М.: Недра.-1987.-216с.

2. Руднев В. К. Кравец С. В., Каслин Н. Д., Супонев В. Н. Машины для бестраншейной прокладки подземных коммуникаций: учебн. пособие под ред. Руднева В. К. Харьков: ООО «Фавор», 2008. - 256c.

3. Супонєв В.М. Створення обладнання для розробки горизонтальних свердловин комбінованими способами статичної дії: монографія. Харків, ХНАДУ, 2018. -196 с.

4. Супонев В.Н., Пенчук В.А., Гусаков В.Н. и др. Точность и управление траекторией прокола грунта// Нові технології в будівництві.-2015.- № 29. -С. 18-22.

5. Плешакова Е.В. Разработка методов обнаружения движущихся металлических объектов в непроводящих и слабопроводящих средах// Автореферат диссертации на соискание ученой степени канд. техн. наук по специальности 25.00.20 «Геомеханика, разрушение горных пород, рудничная аэрогидродинамика, горная теплофизика»-Новосибирск.-2006.

6. Плешакова Е.B. Патент RU 2338876 C1 МПК E21B 47/024, G01V 3/08 Способ определения угла отклонения пневмопробойника от заданной траектории. Опубл.20.11.2008. Бюл. № 32. Патентообладатель: Институт горного дела Сибирского отделения РАН.

7. Сахацкий В.Д., Чепусенко Е.А. Помехозащищенная система измерения угловых координат прокалывающей головки в малогабаритных механизмах управляющего прокола грунта // VII Международная научно-техническая конференция Метрология, информационно- 
измерительные технологии и системы. МИИТС-2020. Тезисы докладов. 18-19 февраля 2020, Харьков. -с.126-127

8. Сахацький В.Д. Використання Wi-Fi технологій для розробки вимірювальної системи визначення координат просторового положення проколюючої головки при безтраншейної прокладки комунікацій / В.Д. Сахацький, Є. О. Чепусенко // Технология приборостроения .- 2018.№ 2.-c. 37- 41.

9. Харвей А.Ф. Техника сверхвысоких частот/ под ред. В.И. Смушкевича. Т.1.- М.: Сов. радио, 1965.-784c.

Сахацький В.Д., Скомороха В.Ю.

Харківський национальный автомобільно- дорожній университет.

\section{ПРИСТРІЙ СПОЛУЧЕННЯ ХВИЛЕВОДНОЇ ЛІНІЇ ПЕРЕДАЧІ В СИСТЕМІ ВИМІРЮВАННЯ ПРОСТОРОВОГО ПОЛОЖЕННЯ ГОЛОВКИ, ЯКА ПРОКОЛЮЄ, МЕХАНІЗМУ ПІДЗЕМНОЇ ПРОКЛАДКИ КОМУНІКАЦІЙНИХ ТРАС}

Анотація: У статті розглядається спосіб підвищення ефективності вимірювальної системи визначення просторового положення головки, яка проколює, механізму проколу трунту, в якій на частоті 5 ГГи порожнисті металеві штанги можуть використовуватися в якості лінії передачі вимірювального сигналу. 3 огляду на те, щьо така лінія за рахунок своєї неоднорідності змінює поляризаиію хвилі, запропонована конструкиія пристрою сполучення круглого хвилеводу з коаксіальним входом приймального пристрою, яка дозволяє на його вході збільшити рівень сигналу. Проведені експериментальні дослідження на макеті лінії передачі з робочою частотою 10 ГГи підтвердили ефективність запропонованого пристрою сполучення.

Ключові слова: круглий хвилевід, коефіцієнт передачі, коаксіальний хвилевід, неоднорідність, деполяризачія хвилі, рівень сигналу.

Sakhatskiy V. D., Skomorokha V. Yu.

Kharkov National Automobile and Highway University

\section{DEVICE FOR INTERFERENCE OF A WAVEGUIDE TRANSMISSION LINE IN THE SYSTEM FOR MEASURING THE SPATIAL POSITION OF THE PUNCHING HEAD OF THE UNDERGROUND LAYING OF THE COMMUNICATION TRAFFIC}

Abstract: The article discusses a way to improve the efficiency of the measuring system for determining the spatial position of the piercing head of the soil puncture mechanism, in which at a frequency of $5 \mathrm{GHz}$, hollow metal rods can be used as a transmission line of the measuring signal. Considering that such a line, due to its inhomogeneity, changes the polarization of the transmitted wave, a design is proposed for a device for interfacing a circular waveguide with a coaxial input of a receiving device, which allows increasing the signal level at its input. The conducted experimental studies on the model of a transmission line with an operating frequency of $10 \mathrm{GHz}$ confirmed the effectiveness of the proposed interface device.

Keywords: circular waveguide, transmission coefficient, coaxial waveguide, heterogeneity, change in wave polarization, signal level. 